\title{
DESAFIOS EDUCACIONAIS NO BRASIL
}

Este é um momento quando a maior parte dos estudantes e trabalhadores brasileiros se veem na condição de desempenho de suas atividades somente a distância, devido à quarentena a que as populações mundiais se submetem na tentativa de deter a pandemia Covid-19. Assim, a entrevista a seguir faz uma reflexão sobre os processos de ensino e aprendizagem nos dias atuais e suas raízes históricas, para questionar o real alcance quantitativo e qualitativo das políticas que envolvem o acesso à educação no país.

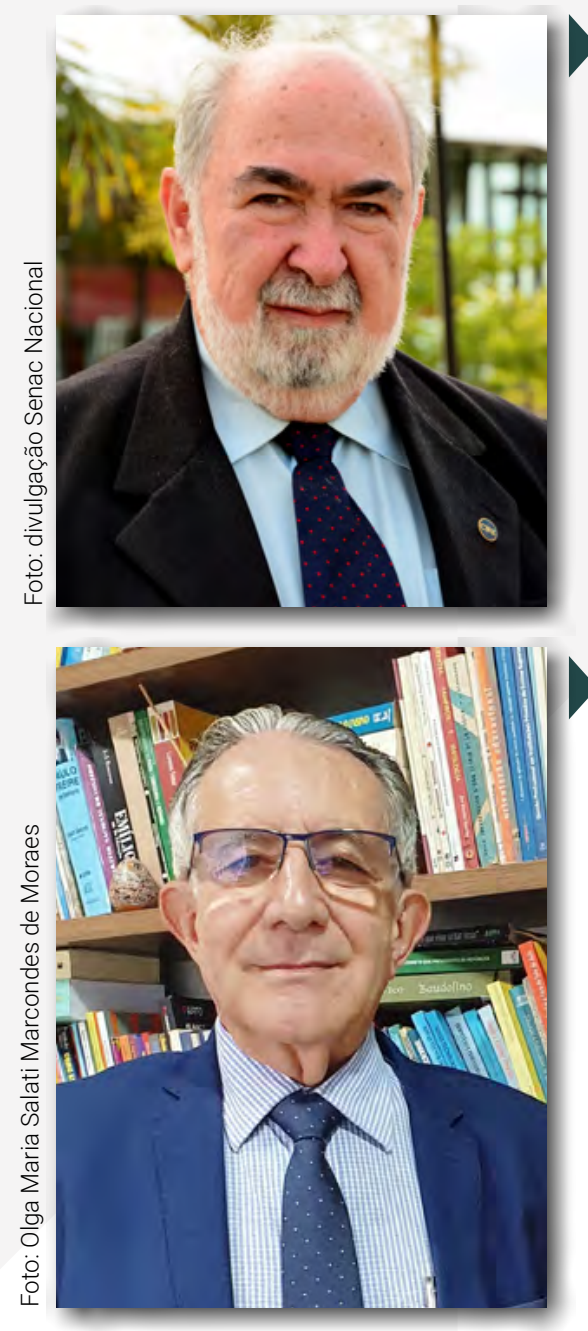

\section{Francisco Aparecido Cordão}

Educador, sociólogo e filósofo. Graduado em Filosofia e Pedagogia. Especialista em Educação Profissional, Administração Educacional e Sociologia da Educação. Tem atuado como Conselheiro nos Conselhos de Educação do Município e do Estado de São Paulo e na Câmara de Educação Básica do Conselho Nacional de Educação (CNE). Representou o Brasil no Mercosul Educacional. Atuou durante mais de 30 anos no Senac em São Paulo. Titular da Cadeira 28 na Academia Paulista de Educação. Presta serviços educacionais a Sistemas, Organizações e Instituições educacionais, tais como Senac, Sesc e Representação da Organização das Nações Unidas para a Educação, a Ciência e a Cultura (Unesco) no Brasil. E-mail: facordao@uol.com.br

\section{Francisco de Moraes}

Consultor educacional, com focos prioritários em educação profissional e educação corporativa. É consultor associado da Peabiru Educacional Ltda. Pedagogo pela Universidade Estadual Paulista "Júlio de Mesquita Filho" (Unesp), com pós-graduação em Didática, Gestão Educacional, Gestão Mercadológica e Empreendedorismo Social. Foi gestor educacional no Senac em São Paulo até 2007, diretor de Escola Técnica Estadual (Etec) no Centro Paula Souza e consultor da Representação da Unesco no Brasil. Integrou o Conselho Estadual de Educação de São Paulo, o Conselho Diretor do Instituto Federal de Educação, Ciência e Tecnologia de São Paulo e o Conselho Superior da rede Senac de Educação a Distância. Autor do livro Empresas-escola: educação para o trabalho versus educação pelo trabalho $(2010,2012)$; coautor dos livros Currículos integrados no ensino médio e na educação profissional: desafios, experiências e propostas (2016) e Educação profissional no Brasil: síntese histórica e perspectivas (2017), todos publicados pela Editora Senac São Paulo. E-mail: fmoraes2007@gmail.com 
FAC - Neste momento crítico para o Brasil e o mundo diante da pandemia decorrente do Covid-19, nossa preocupação, como de muitos educadores brasileiros, está também voltada fortemente para a qualidade da educação brasileira. Nós temos uma grande dívida social em matéria de educação. Mostramos isso muito bem em nossa obra conjunta publicada pela Editora Senac São Paulo, "Educação profissional no Brasil: síntese histórica e perspectivas". Você julga que podemos aproveitar este momento crítico para dar um salto de qualidade em nossa educação nacional, praticando uma educação mais flexível e contextualizada, que realmente faça sentido para os nossos educandos?

FM - Uma afirmação que se tornou chavão por sua fácil aceitação e entendimento é que toda crise tem uma oportunidade como contraponto positivo. Consta que sua origem também é chinesa, como o vetor dessa grave pandemia que nos enclausurou, fez e fará muitas vítimas fatais. Se houver postura orientada para aprendizagens individuais e coletivas, é muito provável que os sobreviventes saiam mais fortes e mais bem estruturados em muitos aspectos da vida social, incluindo o ensino, a educação e, mais importante, a aprendizagem. A necessidade de foco no essencial é a variável que julgo mais relevante por seu maior impacto. Isso se aplica à gestão da crise decorrente da pandemia e é também aplicável à chamada crise de resultados na qualidade do ensino e da educação, mensurável pelas avaliações nos resultados de aprendizagem dos estudantes. O rigor que deve ser enfático na definição das expectativas e metas de aprendizagem precisa ser acompanhado por maior flexibilidade nas possibilidades de opções quanto a métodos, recursos e atividades de aprendizagem. A ampliação das possibilidades de educação a distância com apoio de recursos tecnológicos e de parcerias interinstitucionais para viabilizar aprendizagens essenciais é uma solução parcial já encaminhada em vários contextos educacionais. Essa experiência pode trazer resultados replicáveis para acelerar novos padrões de ensino e aprendizagem, mais eficazes e efetivos quanto aos resultados qualitativos e à ampliação da inclusão de contingentes populacionais ainda excluídos do sistema formal de ensino e educação. É possível que formalidades, rituais, preconceitos, posturas corporativistas e outros entraves ao foco no essencial sejam ao menos parcialmente superados pela distopia decorrente desta crise sem precedentes nas últimas gerações. Infelizmente, há ainda o risco de oportunismos que agravem as disparidades em alguns aspectos e a exclusão social que marca e mancha nossa história de pouco mais de meio milênio. O fator mais importante a considerar, para que haja alguma contrapartida de ganhos com a oportunidade gerada por esta crise, é que o foco na aprendizagem dos estudantes seja acompanhado por cuidados na criação de situações de aprendizagem que eles próprios percebam como relevantes e adequadamente contextualizadas com suas práticas sociais e experiências de vida. Obviamente, isso inclui as oportunidades e possibilidades sustentáveis de trabalho e renda. 
FAC - O Movimento Todos pela Educação, do qual tenho a honra de ser um dos seus sócios-fundadores, apresentou para os candidatos em nossa última eleição federal e estadual "uma proposta suprapartidária de estratégia para a Educação Básica brasileira e prioridades para o Governo Federal em 2019-2022", denominada "Educação Já", destacando a urgência "de melhorar decisivamente a Qualidade da Educação Básica". O Relatório Anual de Acompanhamento do "Educação Já" fez um balanço de 2019 e levantou perspectivas para 2020. Os resultados foram muito baixos nas avaliações de desempenho em relação ao $3^{\circ}$ ano do Ensino Fundamental (alfabetização), bem como no $5^{\circ}$ e no $9^{\circ}$ ano dessa etapa de ensino, e pior ainda em relação ao $3^{\circ}$ ano do Ensino Médio. Resultados similares foram alcançados em outras avaliações de larga escala, tais como Sistema Avaliação Educação Básica (Saeb), Exame Nacional do Ensino Médio (Enem) e Programa Internacional de Avaliação de Estudantes (Pisa). Olhando esse quadro, verificamos que a "estamos muito mal na foto". Entretanto, ao verificar os mais de quinhentos anos de descaso do Brasil em relação à instrução pública do seu povo e comparar com os avanços que conseguimos a partir da aprovação da segunda Lei de Diretrizes e Bases da Educação Nacional (LDB) - Lei n. 9.394/1996, podemos dizer que "aparecemos melhores no filme". Você concorda com isso ou se alinha aos que vislumbram que não teremos nada a comemorar na educação nacional em 2022, o ano de nosso "Bicentenário da Independência"?

FM - Considero que o primeiro e um dos mais importantes desafios da qualidade é superar o desafio da quantidade, para incluir o máximo de crianças e jovens na educação regular. "Nenhum a menos"11,100\% dos brasileiros até 18 anos e dos que ainda não conseguiram completar a educação básica na idade certa é a meta a perseguir. Ainda não chegamos a atingir esse número na Educação Básica, nem mesmo no Ensino Fundamental. Mas avançamos bastante no atendimento quantitativo nos últimos 200 anos. A diminuição da média nos indicadores quantitativos da aprendizagem é uma decorrência que julgo integrar o processo de desenvolvimento da educação nacional, como também ocorreu em muitas outras nações. Em minha opinião, a apregoada "escola risonha e franca", do poeta português Acácio Antunes, cantada em prosa e verso por alguns dos nossos contemporâneos, é mero retrato antigo que foi repaginado e colorido artificialmente pela memória seletiva dos sobreviventes de uma perversa máquina de exclusão social. No nosso tempo de alunos, saíamos melhor alfabetizados do curso primário (atual $5^{\circ}$ ano) do que a média dos atuais concluintes desse período escolar. Isso ocorreu, entretanto, porque a maioria dos que tinham nossa idade nem teve chances de frequentar uma escola ou foi reprovada logo no início e a abandonou. Somos resultado de uma seleção artificial, organizada para ser excludente. Considero que nesse período ocorreram os principais avanços dos dois séculos da "Independência" formalmente concedida ao Brasil em 1822. Assim, apesar de tudo, ainda acredito ser possível alguma comemoração em 2022 quanto à evolução positiva na educação pública. Avançamos menos do que gostaríamos e do que poderíamos ter avançado, especialmente em 
decorrência das pragas sociais que já abordamos em nosso livro conjunto e que sempre atuaram e ainda atuam como freios potentes para conter avanços sociais em geral, com fortes reflexos na educação dos brasileiros: patrimonialismo, escravismo e cartorialismo. Ainda acredito que avançamos e que podemos continuar avançando, apesar de retrocessos que poderiam nos desanimar, mas que também podem ser estímulos adicionais para maior empenho de pessoas que acreditam no potencial transformador da aprendizagem como fator fundamental para desenvolvimento social com justiça e equidade. Comemorar um pouco e acelerar bastante, com base nos sucessos obtidos e com atenção para superar os tropeços e entraves que integram os diagnósticos dos fracassos.

FAC - 0 mundo todo está preocupado com a melhoria da qualidade da educação. Todos estão procurando "fazer o dever de casa" para o seu desenvolvimento, desde a alfabetização até os anos finais de consolidação da Educação Básica, bem como em relação à Educação Superior, de Graduação e de Pós-graduação e, de modo especial, em relação à Educação Profissional. Melhorar a qualidade da educação em todos os seus níveis e modalidades é primordial para que o Brasil se mantenha na economia mundial. Entretanto, o país é um sério candidato a ser o último a erradicar $o$ analfabetismo, tanto $o$ absoluto quanto o funcional. Como enfrentar esse desafio em nosso sistema educacional, neste momento histórico, quando nem chegamos a praticar totalmente a chamada "Educação 3.0" e já se fala em “Educação 4.0" e "Aprendizagem 5.0"?

FM - Creio que a heterogeneidade de nossa realidade social mais ampla é nossa principal marca. Isso é um grande problema, pois significa muita desigualdade, muita injustiça e média de resultados muito baixa. Nosso sistema educacional envolve um conjunto de realidades díspares que tenta englobar. Há dúvidas até sobre a adequação de "sistema educacional" como denominação para esse conjunto de realidades e práticas, que a legislação e as normas qualificam como tal. A realidade brasileira apresenta, em paralelo, práticas e conceitos medievais mesclados com outros contextos modernos ou modernosos. Alguns foram batizados como marcas em países dominantes, outros copiados sem rigor e sem pudor, mas outros foram aqui desenvolvidos com muito trabalho e abnegação, focados em nossa gente e nossa realidade. Da aldeia, ganharam o mundo. Um exemplo é o trabalho de Paulo Freire, com mira nos trabalhadores analfabetos de um vilarejo no sertão nordestino e que até hoje é estudado com destaque e louvor nos grandes centros de disseminação de saber. De fato, não praticamos muito do que poderíamos das chamadas "Educação 3.0", "Educação 4.0" ou "Aprendizagem 5.0". Aliás, nem tenho certeza de que esse fato é tão lamentável. Praticamos um pouco disso tudo, com uma alegoria um tanto carnavalesca, é verdade. Não tenho receitas prontas, nem acredito que alguma receita ou modelo funcione plenamente em nosso quadro de heterogeneidades e potencialidades. Reitero que o desafio da qualidade só pode ser superado a partir da ênfase prioritária e concomitante com o desafio da quantidade. Nenhum 
a menos. Todos cada vez melhores. Avaliar sempre, para descobrir e ampliar os caminhos de sucesso, e para superar os tropeços e os tombos que acompanham quem aprende a caminhar e quem se atreve a correr. O início de um esforço empenhado na erradicação do analfabetismo absoluto ou funcional precisa começar por diminuir para algo próximo de zero a "formação" de jovens analfabetos pelas escolas, pela ausência de escolas ou pela ausência, reprovação e evasão de estudantes. Valorizar prioritariamente e qualificar sempre e muito bem os professores alfabetizadores da educação infantil precedente e dos anos iniciais do Ensino Fundamental é parte essencial do processo. Valorizar significa a remuneração condizente, embora não se esgote nisso. Os países com maior sucesso na Educação Básica de seus cidadãos têm as carreiras docentes entre as mais procuradas pelos melhores estudantes do Ensino Médio e o maior respeito social pelos professores. Honestamente, acredito que há no Brasil algum movimento popular coletivo e de muitas lideranças nesse rumo, apesar de alguns retrocessos aparentes e efetivos. Essa ênfase no Ensino Fundamental é por ser a base de toda a educação subsequente. O Ensino Médio precisa muito mais de contextualização com as realidades próximas e mais amplas, além de maior engajamento e protagonismo dos estudantes em relação aos próprios processos de aprendizagem. Algo similar ocorre com a Educação Superior e na Educação Profissional, embora talvez em menor grau, pois nesses casos ainda há um desafio importante para atendimento à demanda (quantidade) em associação a ganhos qualitativos em busca da excelência sempre almejada.

FAC - Você está escrevendo um novo livro para ser publicado ainda neste ano pela editora Senac São Paulo, com tema e título inicial "Excelência no ensino: caminhos para a gestão da qualidade educacional". Quais os caminhos que você vislumbra para que essa "Excelência no ensino", no caso brasileiro, realmente garanta o alcance de uma "Excelência na aprendizagem", que seja verdadeiramente democrática e supere a enorme dívida social que carregamos?

FM - Os originais do livro estão próximos da metade do texto imaginado. As principais ideias já estão alinhavadas. Pretendo apresentar reflexões e propostas sobre ensino, educação e aprendizagem. Uma das principais ideias é que o ensino é a parte central e mais planejada da educação. Outra reflexão é que o ensino só se efetiva com a aprendizagem dos estudantes. Logo, a excelência no ensino só pode ocorrer se houver excelência na aprendizagem. A excelência da infraestrutura das escolas, o currículo dos professores, a pompa e a beleza das apostilas e livros didáticos, dos vídeos e dos materiais de propaganda podem ser condições eventualmente integrantes do processo e facilitadoras dos resultados e da vontade de aprender dos estudantes. A excelência do ensino, entretanto, não se resume a isso. Aliás, na maioria das situações, nem depende muito de tudo isso, embora sempre haja um mínimo essencial que precisa ser garantido para viabilizar chances de sucesso. É a excelência da aprendizagem que define a excelência do ensino. Aulas brilhantes na forma 
e mesmo no conteúdo, se não proporcionam aprendizagem, têm o mesmo valor de um cheque pomposo que só contenha uma sucessão de zeros nos algarismos e por extenso: conjunto vazio. Já afirmei que não tenho soluções prontas e desconfio muito de quem afirma ter. Vislumbro trilhas que podem se transformar em caminhos, se forem trilhadas por bons caminhantes. Foco na aprendizagem, abnegação constante, esperança ativa, com envolvimento dos estudantes no seu caminhar e dos professores e demais atores do ensino no esforço de também aprender são algumas dessas trilhas que vislumbro. Há galhos, pedras e espinhos nessas trilhas. Há, também, flores e riachos rumorejantes para os que nelas se aventurarem. Os gestores educacionais, desde os níveis gerenciais médios até os diretores, supervisores, reitores e os líderes em redes públicas ou privadas, secretarias municipais ou estaduais, órgãos ministeriais e cargos políticos normalmente conseguem mais sucesso quando se dedicam a atrapalhar do que quando interferem açodadamente com a boa intenção que gera muitos malefícios. Assim, um dos caminhos que vislumbro é que tais gestores se dediquem mais a estimular positivamente e a valorizar efetivamente as boas experiências e as práticas de ensino que garantam mais situações de excelência na aprendizagem.

\section{Nota}

1 Não por acaso, "Nenhum a menos" é também o título de um emocionante filme chinês de 1999, dirigido por Zhang Yimou. Trata de uma escola precária na zona rural, na qual uma professora substituta faz de tudo para evitar qualquer evasão de seus estudantes. 